(a) OPEN ACCESS

\title{
Intimate partner violence and social connection among married women in rural Bangladesh
}

\author{
Laura W Stoff (1) , ${ }^{1}$ Lisa M Bates, ${ }^{2}$ Sidney Ruth Schuler, ${ }^{3}$ Lynette M Renner, ${ }^{4}$ \\ Darin J Erickson, ${ }^{1}$ Theresa L Osypuk ${ }^{1}$
}

${ }^{1}$ Epidemiology and Community Health, University of Minnesota School of Public Health,

Minneapolis, Minnesota, USA ${ }^{2}$ Epidemiology, Columbia University Mailman School of Public Health, New York, New York, USA

${ }^{3}$ Social and Behavioral Health Sciences, FHI 360, Washington, DC, USA

${ }^{4}$ University of Minnesota School of Social Work, Saint Paul, Minnesota, USA

\section{Correspondence to}

Ms Laura W Stoff, Epidemiology and Community Health,

University of Minnesota School of Public Health, Minneapolis, MN 55455-0381, USA; Iwstoff@gmail.com

Received 4 August 2020 Accepted 13 May 2021

\section{Check for updates}

(C) Author(s) (or their employer(s)) 2021. Re-use permitted under CC BY-NC. No commercial re-use. See rights and permissions. Published by BMJ.

To cite: Stoff LW, Bates LM, Schuler SR, et al. J Epidemiol Community Health Epub ahead of print: [please include Day Month Year]. doi:10.1136/jech-2020214843

\section{ABSTRACT}

Background Intimate partner violence (IPV) is high among married women in Bangladesh. Social isolation is a well-established correlate of women's exposure to IPV, but the role of such factors in low-income and middleincome countries is not well understood. In this study, we explore whether social connection is protective against IPV among married women in rural Bangladesh.

Methods Data were drawn from a multistage, stratified, population-based longitudinal sample of 3355 married women in rural Bangladesh, who were surveyed on individual and contextual risk factors of IPV. Negative binomial regression models were used to estimate the association between three different domains of social connection (natal family contact, female companionship and instrumental social support), measured at baseline in 2013, and the risk of three different forms of IPV (psychological, physical and sexual), approximately 10 months later, adjusted for woman's level of education, spouse's level of education, level of household wealth, age and age of marriage.

Results Adjusted models showed that instrumental social support was associated with a lower risk of past year psychological IPV (risk ratio $(\mathrm{RR})=0.84,95 \% \mathrm{Cl}$ 0.769 to 0.914$)$, sexual IPV (RR $=0.90,95 \% \mathrm{Cl} 0.822$ to 0.997 ) and physical IPV (RR $=0.81,95 \% \mathrm{Cl} 0.718$ to 0.937 ). Natal family contact was also associated with a lower risk of each type of IPV, but not in a graded fashion. Less consistent associations were observed with female companionship.

Conclusion Our findings suggest that social connection, particularly in the form of instrumental support, may protect married women in rural Bangladesh from experiencing IPV.

Intimate partner violence (IPV) is a pervasive public health concern that is detrimental to the health and well-being of women worldwide. ${ }^{1}$ Defined as any behaviour of an intimate partner that causes some type of physical, psychological or sexual harm, ${ }^{1}$ women are at significantly greater risk of experiencing IPV than men, ${ }^{1}$ and experiences of IPV generally represent patterns of ongoing abuse. ${ }^{2}$ Rates of IPV victimisation remain particularly high among women in South Asia. ${ }^{3}$ For example, married women in Bangladesh report lifetime IPV victimisation rates ranging from $53 \%$ to $95 \% .^{4-6}$

Psychological IPV is the most common and frequent form of IPV experienced by women in rural Bangladesh, with $67 \%$ of women experiencing psychological IPV in their lifetimes. ${ }^{78}$ However, physical and sexual IPV risks are also high, with $32 \%-47 \%$ of women reporting lifetime physical and $15 \%-26 \%$ of women reporting lifetime sexual $\mathrm{IPV}^{9}{ }^{10}$; these three IPV types often co-occur. Poor health outcomes associated with IPV include injuries, pelvic pain, irritable bowel syndrome, reproductive tract infection, memory loss, unwanted pregnancy, depression, distress and suicidal ideation. $^{2} 1112$ Women of reproductive age are at particularly high risk for IPV victimisation. ${ }^{11}{ }^{13-15}$

The relationship between social isolation and IPV in high-resource settings like the USA is well established. ${ }^{16-21}$ For example, in a US population-based sample, women experienced a lower likelihood of IPV as their levels of family support increased. ${ }^{17}$ However, to our knowledge, only a few researchers have explored this relationship empirically in low-income settings. As exceptions, greater social support has been associated with lower partner abuse in Pakistan. ${ }^{16}$ In a sample of pregnant women in Tanzania, financial social support and monthly communication with family members were associated with lower odds of experiencing IPV and repeated abuse. ${ }^{19}$ The present study adds to the limited body of empirical research exploring the relationship between social connection and IPV in low-income settings.

Research in high-income settings suggests that social isolation may increase IPV risk through two distinct mechanisms: (1) women who are more socially isolated are more vulnerable to entering into and staying in abusive relationships ${ }^{2022}$; and (2) withholding social relationships from women is a common tactic of abusive partners to isolate their victims. ${ }^{22}$ However, in rural Bangladesh, a context in which IPV is highly normative and women have little to no recourse to exit an abusive marriage, ${ }^{10}{ }^{12}$ it is likely that the mechanisms behind social connection and IPV operate differently than in other settings. For example, women who are more socially connected in Bangladesh may be at lower risk of IPV, which is less socially normative and more likely to provoke community opprobrium or intervention. ${ }^{15}$ To explore this hypothesis, we use a severity measure of IPV rather than the typical dichotomous measure commonly used in empirical studies. This operationalisation of IPV allows us to identify whether women with more social connections are more likely to have less severe levels of IPV. Using IPV severity, we explore effects of three different types of social connection (natal family contact, female companionship, instrumental social support) on married women's risk of experiencing physical, psychological and sexual IPV in rural Bangladesh. 


\section{METHODS}

\section{Sample}

We used data from a population based, multistage prospective cohort study which aimed to identify the contextual determinants of IPV risk among married women in rural Bangladesh in 2013-2014. ${ }^{14}$ Villages and households were selected through stratified random sampling procedures. In the first stage, the Bangladesh 2011 census was used to stratify districts into four groups based on the magnitude and direction of girls' versus boys' school attendance: (1) girls' attendance lower by 9\%-23\%, (2) lower by $4 \%-8 \%,(3)$ lower by $0 \%-3 \%$ and (4) higher by 1\%-9\%. Within each stratum, villages with more than 200 and less than 500 households were eligible for selection, yielding a sample of 78 villages at baseline. In each sampled village, all households were enumerated; within sampled households, one eligible individual was selected per household for the study. For households where multiple married women were eligible, one individual was randomly selected to participate. Women in the current analysis were married 4-12 years, and ranging in age from 16 to 37 years, at baseline. ${ }^{14}$

Participants completed a baseline in-person interview between June and September 2013, and response rates were 94.7\% ( $\mathrm{N}=3902)$. Approximately 10 months later, participants completed a follow-up in-person interview, where response rates were $86.3 \%$ (in 2014; $\mathrm{N}=3369, \mathrm{~N}=77$ villages; 1 village lost to a flood). A total of 3355 (81.8\%) married women completed both baseline and follow-up interviews, and are the focus for the current study.

The study followed WHO guidelines for research on IPV to protect the safety of participants and interviewers. ${ }^{23}$ All interviews were conducted in-person, at the participants' homes, by masters-level trained, female Bangladeshi interviewers. At the completion of each interview, each participant was informed of their rights under local law, and provided with information about the nearest legal and health-related services.

\section{Variables}

\section{IPV outcomes}

Incidence of psychological, physical and sexual IPV was separately measured using an adaptation of the Revised Conflict Tactics Scale (CTS2) ${ }^{24}$ and the WHO standardised questionnaire on IPV. ${ }^{2}$ Sample items from this scale ask if the respondent's husband has 'done things that scared or intimidated you on purpose,' 'kicked, dragged, or hit you repeatedly,' and 'physically forced you to have sexual intercourse when you did not want to.' The CTS2 has been validated for use in heterosexual couples, ${ }^{25}$ and has been used previously in Bangladesh. ${ }^{2}$

We used women's report of IPV at follow-up, which was measured 10 months after baseline, indicating past-year incidence of IPV. Baseline IPV measures were not available for this analysis due to difficulties with data collection. To operationalise IPV, we generated a severity score, used previously with these data, ${ }^{15}$ for a more granular estimation of IPV exposure than a binary measure of whether or not IPV occurred at all during the reference period. ${ }^{15}$ For each IPV type (psychological, physical and sexual), women were asked if they had experienced specific behaviours in the last year. For each behaviour a woman endorsed, she reported the frequency with which it occurred. Frequency response options were: 1 or 2 times, (coded ' 1 ') 3-5 times, (coded '2') 6-10 times, (coded ' 3 ') 11-20 times, (coded ' 4 ') and more than 20 times (coded ' 5 ') in the past year. These frequency scores for each IPV type were then summed to calculate a type-specific severity scale. Each IPV scale contained a different number of items (ie, physical $=7$; psychological $=10$; sexual=3), resulting in different potential ranges (eg, 0-40 for psychological, 0-28 for physical and 0-12 for sexual IPV). Spearman's rank-order correlations were run to determine the relationship between each IPV severity outcome. Correlations were all significant $(\mathrm{p}<0.0001)$ with rho values ranging from 0.46 to 0.59 .

\section{Social connection exposures}

We used three items from the baseline survey to capture different domains of social connection hypothesised to influence risk of IPV: (1) natal family contact; (2) female companionship; and (3) instrumental social support. Together, the three items capture differences in both the source and type of social connection. The intercorrelation was low; therefore, rather than including all social connection variables in one model, we chose to measure each exposure separately in order to generate associations between each exposure and each outcome. Natal family contact measured the number of times participants reported seeing members of their natal family in the past year $(0-1,2-5,6-10$ or more than 10 times). Female companionship was captured by the frequency with which women reported visiting other women in the village just for socialising, (never, rarely, sometimes, often). Instrumental social support was measured with a binary item indicating if participants had someone in the village to go to when they are in financial trouble, sick or need help with some other problem. Higher values indicate higher social connection.

\section{Confounders}

Previous research suggests a strong link between socioeconomic and demographic factors and risk of IPV. ${ }^{26}$ Thus, we included the following covariates measured at baseline as potential confounders in final models if they were significantly associated with both the exposure (social connection) and outcome (IPV): age; age at marriage; woman's highest attended level of education; spouse's highest attended level of education; and level of household wealth. Level of household wealth was measured by a principal components analysis factor score derived from 19 items loading on the principal factor, and modelled as tertiles. ${ }^{27-29}$ See table 1 for operationalisation of these variables.

\section{Statistical analyses}

We generated descriptive statistics and frequency histograms of each IPV outcome. Histograms revealed heavily-skewed nonnormal distributions of IPV, which are common due to a preponderance of zeroes.

We examined bivariate associations between each social connection exposure and IPV outcome using analysis of variance (ANOVA) comparisons of means. We specified negative binomial models to account for the highly skewed, zero-inflated distribution of IPV severity scores, which is a more flexible model than Poisson, ${ }^{30}$ accommodating over-dispersion in heavily skewed distributions. Such models are often used for modelling count outcomes in violence research, and with the CTS2. ${ }^{31} 32$ We adjusted for the complex sample design; all bivariate and negative binomial models were adjusted for sampling weights, stratified design and clustering.

We fit nine multilevel negative binomial regression models to assess the crude and covariate-adjusted associations between social connection and IPV. Because crude and adjusted results were so similar, we present only adjusted models. To account for multiple comparisons, we adjusted the threshold of significance to $\mathrm{p} \leq 0.01$. We chose this multiple adjustment technique because 
Table 1 Descriptive characteristics of study sample: married women in rural Bangladesh, 2013-2014 ( $\mathrm{N}=3355)$

\begin{tabular}{|c|c|c|}
\hline & Mean (SE) or \% & Range \\
\hline \multicolumn{3}{|c|}{ Intimate partner violence (IPV) severity score * } \\
\hline Physical IPV & $1.8(3.1)$ & $1-26$ \\
\hline Psychological IPV & $4.2(5.3)$ & $1-40$ \\
\hline Sexual IPV & $2.0(2.4)$ & $1-12$ \\
\hline \multicolumn{3}{|l|}{ Social connection, \% } \\
\hline Instrumental support† & $70.4 \%$ & \\
\hline \multicolumn{3}{|l|}{ Natal family contactł } \\
\hline $0-1$ times & $7.9 \%$ & \\
\hline $2-5$ times & $35.0 \%$ & \\
\hline $6-10$ times & $19.9 \%$ & \\
\hline$>10$ times & $37.3 \%$ & \\
\hline \multicolumn{3}{|l|}{ Female companionship§ } \\
\hline Never & $8.4 \%$ & \\
\hline Rarely & $9.3 \%$ & \\
\hline Sometimes & $42.9 \%$ & \\
\hline Often & $39.5 \%$ & \\
\hline Age in years (mean) & $24.4(0.1)$ & $16-37$ \\
\hline Age at first marriage in years (mean) & $16.4(0.1)$ & $10-28$ \\
\hline Number of lifetime births (mean) & $1.8(0.1)$ & $0-8$ \\
\hline \multicolumn{3}{|l|}{ Highest level of education attended, \% } \\
\hline Less than primary school & $10.2 \%$ & \\
\hline Primary school & $27.1 \%$ & \\
\hline Secondary school & $54.7 \%$ & \\
\hline College or higher & $8.0 \%$ & \\
\hline \multicolumn{3}{|c|}{ Highest level of education attended by spouse, $\%$} \\
\hline Less than primary school & $22.5 \%$ & \\
\hline Primary school & $32.9 \%$ & \\
\hline Secondary school & $32.0 \%$ & \\
\hline College or higher & $12.6 \%$ & \\
\hline \multicolumn{3}{|l|}{ Level of household wealth, \% } \\
\hline Low & $33.3 \%$ & \\
\hline Medium & $33.5 \%$ & \\
\hline High & $33.2 \%$ & \\
\hline
\end{tabular}

Descriptive statistics generated from proc surveymeans and proc surveyfreq, and adjusted for sampling weights, clusters, and stratified design. Standard errors generated from unadjusted, unweighted commands.

${ }^{*}$ Actual ranges of IPV severity scores are presented; theoretical ranges are: 0-28 (physical), 0-40 (psychological) and 0-12 (sexual).

tInstrumental support: "Do you have someone in the village to go to when they are in financial trouble, sick, or need help with some other problem?" (Y/N).

¥Natal family contact: "How often have you seen members of your natal family in the past year?" (0-1 times, 2-5 times, 6-10 times, more than 10 times).

$\S$ Female companionship: "How often do you visit other women in the village just for socializing?" (Never, Rarely, Sometimes, Often).

traditional multiple test corrections such as Bonferroni tend to overcorrect, resulting in greater type II error. ${ }^{33}$ All analyses were performed in SAS V.9.4. ${ }^{34}$

\section{RESULTS}

\section{Descriptive data}

On average, women were 24.4 years old, first married by age 16.4 and had 1.8 lifetime births at baseline (table 1). Approximately $55 \%$ of women had attended up to secondary school (high school), and 8\% had attended college. Approximately $32 \%$ of spouses had attended up to secondary school, and $13 \%$ attended college. Mean IPV severity scores were 1.77 for physical IPV, 4.21 for psychological IPV and 2.01 for sexual IPV.

In terms of social connection, $70 \%$ of women reported receiving instrumental support, $57 \%$ reported seeing members of their natal family at least six times in the past year including $37 \%$ who had seen natal family members more than 10 times in the past year. Conversely, $8 \%$ of women reported low levels of natal family contact (one time or less in the past year), $8 \%$ of women reported never experiencing female companionship and another 9\% reported rarely experiencing any female companionship.

\section{Bivariate analyses}

ANOVA tests illustrate bivariate associations between social connection and IPV severity (table 2). The presence (compared with absence) of instrumental support was significantly associated with lower mean IPV severity score, for all three forms of IPV. Patterns for the other indicators of social connection were less consistent. Although there does not appear to be a graded association between IPV severity and female companionship, women who reported socialising with other women often, compared with the other categories of female companionship, consistently had the lowest mean IPV severity scores.

\section{Negative binomial regression results}

Instrumental support yielded the strongest and most consistent protective association with past-year IPV, across all types (table 3). Women reporting instrumental support experienced $16 \%$ lower risk of past-year psychological IPV (risk ratio $(\mathrm{RR})=0.84,95 \% \mathrm{CI} 0.769$ to 0.914$), 10 \%$ lower risk of pastyear sexual IPV $(\mathrm{RR}=0.90,95 \% \mathrm{CI} 0.822$ to 0.997$)$ and $19 \%$ lower risk of past-year physical IPV $(\mathrm{RR}=0.81,95 \% \mathrm{CI} 0.718$ to 0.937 ), compared with those without instrumental support.

Overall, as operationalised, the association between IPV and natal family contact in the past year was not statistically significant for any type of IPV. However, there does appear to be a threshold protective association: the risk of IPV is similarly lower for all three frequency categories above the reference category of 0-1 natal family visits a year, suggesting that women who are very isolated from their natal families are at increased risk but, beyond that, greater frequency of contact does not confer added protection.

Results suggested that female companionship may be protective against IPV, but were imprecise. Compared with women who never socialised with other women in the village, women who often socialised experienced $11 \%$ reduced risk of psychological IPV $(\mathrm{RR}=0.89,95 \% \mathrm{CI} 0.813$ to 1.101$)$, and $15 \%$ reduced risk of physical IPV (RR $=0.85,95 \%$ CI 0.712 to 1.138$)$, although these associations were not significant. The RR associated with sexual IPV was similar $(\mathrm{RR}=0.89$, 95\% CI 0.798 to 1.115$)$; however, the estimates for sexual and physical IPV were less precise and not statistically significant.

\section{DISCUSSION}

The objectives of this study were to examine if different forms of social connection were associated with lower severity of past-year psychological, sexual and physical IPV among a population-based prospective panel study of married women in rural Bangladesh. We found that women reporting instrumental support also reported lower IPV severity, for all three types of IPV, in adjusted models. The findings for other forms of social connection-contact with natal family and frequency of socialisation with female village neighbours-also suggested a protective effect but the evidence was more equivocal. 
Table 2 Bivariate analyses: intimate partner violence (IPV) severity by social connection among study sample ( $N=3355)$

\begin{tabular}{|c|c|c|c|c|c|c|}
\hline \multirow[b]{2}{*}{ Variable } & \multicolumn{2}{|c|}{ Psychological IPV } & \multicolumn{2}{|c|}{ Sexual IPV } & \multicolumn{2}{|c|}{ Physical IPV } \\
\hline & Mean & $P$ value & Mean & $P$ value & Mean & $P$ value \\
\hline \multicolumn{7}{|c|}{ Instrumental support } \\
\hline Yes & 1.61 & $<0.001^{* *}$ & 1.92 & 0.001 ** & 1.61 & $<0.001^{* *}$ \\
\hline No & 2.14 & & 2.23 & & 2.14 & \\
\hline \multicolumn{7}{|c|}{ Natal family contact } \\
\hline$>10$ times & 4.17 & 0.198 & 1.92 & 0.240 & 1.72 & 0.292 \\
\hline $6-10$ times & 3.93 & & 1.99 & & 1.78 & \\
\hline $2-5$ times & 4.25 & & 2.03 & & 1.76 & \\
\hline $0-1$ times & 4.92 & & 2.45 & & 2.03 & \\
\hline \multicolumn{7}{|c|}{ Female companionship } \\
\hline Often & 3.95 & $0.008^{*}$ & 1.91 & 0.097 & 1.68 & 0.021 \\
\hline Sometimes & 4.24 & & 2.04 & & 1.74 & \\
\hline Rarely & 5.18 & & 2.36 & & 2.21 & \\
\hline Never & 4.18 & & 2.02 & & 1.86 & \\
\hline
\end{tabular}

Means generated from proc surveymeans, and adjusted for sampling weights, clusters, and stratified design.

Comparison of means $p$ values generated from F-tests using proc anova and adjusted for clusters and stratified design.

${ }^{*} \mathrm{P} \leq 0.01 ;{ }^{* *} \mathrm{p} \leq 0.001$.

Instrumental support was consistently associated with lower risks of IPV. These findings align with those of previous research for women during pregnancy in rural Tanzania ${ }^{19}$ and rural Bangladesh. ${ }^{35}$ Instrumental support is defined as having someone to assist with financial, health, or other difficulties, and this form of social connection was consistently associated with lower IPV in our study. These findings point to the broad impact that instrumental support may play in limiting women's exposure to violence. In this setting where violence is highly prevalent and normalised, the provision of instrumental support, or possibly other types of social support or social connection, may mean a friend or family member intervenes in cases of extreme violence. Our severity measure of IPV allows us to interpret findings as limiting or diminishing the exposure of violence-which often happens through intervention from family and friends-rather than preventing it altogether, which may be less likely in this setting. ${ }^{15}$

Overall, the results for natal family contact suggest a threshold effect whereby receiving any amount of natal family contact more than once a year is associated with a lower risk of IPV. Women in rural Bangladesh typically marry outside of their village, and move away from their natal family, ${ }^{10}$ so physical distance can represent a significant barrier to accessing natal family support. Women who marry within their natal village likely have more contact with natal family members, including greater support, and potentially greater recourse in an abusive marriage. Families may intervene to reduce IPV or women may have a viable option to return to their natal families if abuse is extreme. ${ }^{710}$

Finally, our results for female companionship were somewhat consistent with other research in Bangladesh indicating that

Table 3 Multilevel negative binomial regression models assessing the effects of social connection on past-year intimate partner violence (IPV) severity $(\mathrm{N}=3355)$

\begin{tabular}{|c|c|c|c|c|c|c|c|c|c|}
\hline \multirow[b]{2}{*}{ Model } & \multicolumn{3}{|c|}{ Psychological IPV } & \multicolumn{3}{|c|}{ Sexual IPV } & \multicolumn{3}{|c|}{ Physical IPV } \\
\hline & RR & $95 \% \mathrm{Cl}$ & $P$ valuet & $\mathbf{R R}$ & $95 \% \mathrm{Cl}$ & $P$ value & RR & $95 \% \mathrm{Cl}$ & $P$ value \\
\hline \multicolumn{10}{|c|}{ Instrumental support } \\
\hline Yes & 0.84 & 0.769 to 0.914 & $<0.001 * *$ & 0.90 & 0.822 to 0.997 & 0.042 & 0.81 & 0.718 to 0.937 & $0.002^{*}$ \\
\hline No & REF & & & REF & & & REF & & \\
\hline \multicolumn{10}{|c|}{ Natal family contact } \\
\hline$>10$ times & 0.86 & 0.729 to 0.996 & 0.106 & 0.82 & 0.680 to 0.962 & 0.173 & 0.88 & 0.657 to 1.067 & 0.631 \\
\hline $6-10$ times & 0.82 & 0.677 to 0.948 & & 0.86 & 0.692 to 1.004 & & 0.91 & 0.654 to 1.125 & \\
\hline $2-5$ times & 0.89 & 0.774 to 1.006 & & 0.85 & 0.700 to 0.993 & & 0.86 & 0.662 to 1.079 & \\
\hline $0-1$ times & REF & & & REF & & & REF & & \\
\hline \multicolumn{10}{|c|}{ Female companionship } \\
\hline Often & 0.89 & 0.813 to 1.101 & 0.012 & 0.89 & 0.798 to 1.115 & 0.206 & 0.85 & 0.712 to 1.138 & 0.083 \\
\hline Sometimes & 0.95 & 0.868 to 1.173 & & 0.95 & 0.840 to 1.171 & & 0.87 & 0.730 to 1.164 & \\
\hline Rarely & 1.12 & 1.024 to 1.492 & & 1.05 & 0.931 to 1.411 & & 1.09 & 0.885 to 1.587 & \\
\hline Never & REF & & & REF & & & REF & & \\
\hline
\end{tabular}

Models adjusted for the following covariates: respondent's level of education, spouse's level of education, level of household wealth, age and age of marriage.

Results generated from proc genmod and adjusted for sampling weights, clusters and stratified design.

${ }^{*} \mathrm{P} \leq 0.01 ;{ }^{*} \mathrm{p} \leq 0.001$.

tP value based on results from type III analysis. 
friends and neighbours are useful sources of social connection, ${ }^{10}$ but serve as less frequent sources of support than immediate family members. ${ }^{35}$ Overall, female companionship exhibited weaker associations with IPV than other forms of social connection. However, similar to natal family contact, the pattern of associations between female companionship and IPV suggests a threshold effect whereby women who never or rarely socialise with other women in the village are at highest risk of IPV severity. These results could be due to a number of factors, one of which could be women's experience of controlling behaviours by their partner. The WHO Multi-country Study on Women's Health and Domestic Violence against Women ${ }^{2}$ found that women who experienced abuse were more likely to report controlling behaviours by their partners, including keeping her from socialising with friends and/or family, ignoring her and restricting her from accessing care and support.

The design of our study contributes significant strengths to the research evidence. First, the population-based design allows for high generalisability for married women in rural Bangladesh. We also controlled for the geographic design features in our analytic plan, including clustering. Modelling severity of IPV provided a more robust measure, by leveraging more information on the distribution of IPV severity, in lieu of simple binary assessments. ${ }^{15}$ As such, we were able to incorporate factors such as prevalence, diversity, and frequency of behaviours into the IPV measures. Additionally, we controlled for several potential confounders, to better estimate the effects of social connection, although admittedly as with any observational study, potential uncontrolled confounding remains a possibility.

Our results suggest that married women in rural Bangladesh would benefit from strategies aimed at both providing and accessing support, particularly instrumental support. One way to increase instrumental support is by providing opportunities for women to affiliate and identify with others around common endeavours, particularly economic endeavours. Men are more likely to be supportive of these because of their potential value to themselves and their families. Widespread existing interventions such as microcredit, skills training and local industries employing women may promote women's access to instrumental support if designed to encourage group interaction and collaboration. ${ }^{36}$ Systems-level interventions such as these can improve women's access to instrumental support by promoting independence and collective empowerment of women.

\section{Limitations}

Despite this study's notable strengths, we encountered some limitations. Our operationalisation of the exposures may not fully capture social connection. Common measures exist, such as Cohen's Social Network Index ${ }^{37}$ and the Berkman-Syme Social Network Index, ${ }^{38}$ but there is no gold standard. Although we leveraged a prospective study that established approximate temporal ordering between exposure and IPV, it is possible that reverse causality is at play, because a woman's prior experience of IPV could influence her social exposures.

\section{CONCLUSIONS}

In conclusion, we found that women reporting social connection, particularly instrumental support, exhibited lower IPV severity in the low-income context of rural Bangladesh. As lifetime risk of IPV victimisation among married women in low and middle-income countries remains high, strategies to incorporate social support may aid efforts to reduce the risk of IPV victimisation and its effects.

\section{What is already known on this subject}

- Married women in rural Bangladesh report high rates of intimate partner violence (IPV), and research in high-income settings suggests that social isolation is a risk factor of IPV.

\section{What this study adds}

- Social connection is understudied in low to middle-income settings. This study documents the association between social connection and IPV severity among married women in rural Bangladesh, whereby instrumental support and natal family contact are both associated with reduced risk of IPV severity. Interventions to reduce IPV victimisation in low to middleincome settings may benefit from focusing on increasing social support in women's social networks.

Contributors SRS and LB contributed to the design and conduct of the origina data collection. They also contributed to the final manuscript. LR and DJE advised on content and methods. TLO acted as the primary advisor to LS, who took the lead on the study and wrote the bulk of the final manuscript.

Funding This study was supported by research grant R01HD061630 from the National Institute of Child Health and Development (PI Schuler).

Competing interests None declared.

Patient consent for publication Not required.

Ethics approval The Institutional Review Boards (IRBs) of the International Center for Diarrheal Disease Research, Bangladesh (icddr,b), FHI 360, and the University of Minnesota approved the initial study and primary data collection methods. The University of Minnesota IRB approved the current study as Non-Human Research due to being a secondary data analysis.

Provenance and peer review Not commissioned; externally peer reviewed.

Data availability statement Data are available upon reasonable request. An individual who wishes to use the data must send a written request to the Principal Investigator stating the name and affiliation of the applicant, the purpose of the analysis, how the data will be used and disseminated, and a brief summary of the analyses to be performed. Following approval of the request by the $\mathrm{PI}$, datasets and codebooks will be made available. Identified data will not be shared.

Open access This is an open access article distributed in accordance with the Creative Commons Attribution Non Commercial (CC BY-NC 4.0) license, which permits others to distribute, remix, adapt, build upon this work non-commercially, and license their derivative works on different terms, provided the original work is properly cited, appropriate credit is given, any changes made indicated, and the use is non-commercial. See: http://creativecommons.org/licenses/by-nc/4.0/.

\section{ORCID iD}

Laura W Stoff http://orcid.org/0000-0003-0614-2977

\section{REFERENCES}

1 Heise L, Garcia-Moreno C. Violence by intimate partners. World Report on Violence and Health 2002:87-121.

2 Garcia-Moreno C, Jansen HAFM, Ellsberg M, et al. Prevalence of intimate partner violence: findings from the WHO multi-country study on women's health and domestic violence. Lancet 2006;368:1260-9.

3 Devries KM, Mak JYT, García-Moreno C, et al. Global health. The global prevalence of intimate partner violence against women. Science 2013;340:1527-8.

4 Azziz-Baumgartner E, Homaira N, Hamadani JD, et al. The prevalence and impact of intimate partner violence on maternal distress in a community of low-income Bangladeshi and displaced ethnic Bihari mothers: Dhaka, 2008-2009. Violence Against Women 2014:20:59-73.

5 Ziaei S, Naved RT, Ekström E-C. Women's exposure to intimate partner violence and child malnutrition: findings from demographic and health surveys in Bangladesh. Matern Child Nutr 2014;10:347-59.

6 Bangladesh Bureau of Statistics, Ministry of Planning, Government of the People's Republic of Bangladesh. Report on violence against women survey 2015. Dhaka, Bangladesh: Statistics and Informatics Division, 2016. 
7 Bhuiya A, Sharmin T, Hanifi SMA. Nature of domestic violence against women in a rural area of Bangladesh: implication for preventive interventions. J Health Popul Nutr 2003;21:48-54.

8 Koenig MA, Ahmed S, Hossain MB, et al. Women's status and domestic violence in rural Bangladesh: individual- and community-level effects. Demography 2003:40:269-88.

9 Naved RT. Sexual violence towards married women in Bangladesh. Arch Sex Behav 2013:42:595-602.

10 Naved RT, Azim S, Bhuiya A, et al. Physical violence by husbands: magnitude, disclosure and help-seeking behavior of women in Bangladesh. Soc Sci Med 2006;62:2917-29.

11 Salam A, Alim A, Noguchi T. Spousal abuse against women and its consequences on reproductive health: a study in the urban slums in Bangladesh. Matern Child Health $J$ 2006;10:83-94.

12 Schuler SR, Yount KM, Lenzi R. Justification of wife beating in rural Bangladesh: a qualitative analysis of gender differences in responses to survey questions. Violence Against Women 2012;18:1177-91.

13 Naved RT, Akhtar N. Spousal violence against women and suicidal ideation in Bangladesh. Womens Health Issues 2008:18:442-52.

14 Yount KM, Crandall A, Cheong YF, et al. Child marriage and intimate partner violence in rural Bangladesh: a longitudinal multilevel analysis. Demography 2016:53:1821-52.

15 Esie P, Osypuk TL, Schuler SR, et al. Intimate partner violence and depression in rural Bangladesh: accounting for violence severity in a high prevalence setting. SSM Popul Health 2019;7:100368

16 Farid M, Saleem S, Karim MS, et al. Spousal abuse during pregnancy in Karachi, Pakistan. Int J Gynaecol Obstet 2008;101:141-5.

17 Wright EM. The relationship between social support and intimate partner violence in neighborhood context. Crime \& Delinquency 2015;61:1333-59.

18 Nguyen TH, Ngo TV, Nguyen VD, et al. Intimate partner violence during pregnancy in Vietnam: prevalence, risk factors and the role of social support. Glob Health Action 2018;11:1638052

19 Sigalla GN, Rasch V, Gammeltoft T, et al. Social support and intimate partner violence during pregnancy among women attending antenatal care in Moshi Municipality, Northern Tanzania. BMC Public Health 2017:17:240.

20 Lanier C, Maume MO. Intimate partner violence and social isolation across the rural/ urban divide. Violence Against Women 2009;15:1311-30.

21 Cohabiting SJ. And marital aggression: the role of social isolation. Journal of Marriage and Family 1991;53:669-80.
22 Capaldi DM, Knoble NB, Shortt JW, et al. A systematic review of risk factors for intimate partner violence. Partner Abuse 2012;3:231-80.

23 WHO. Putting women first: ethical and safety recommendations for research on domestic violence against women. Geneva, Switzerland: World Health Organization, 2001

24 Straus MA, Douglas EM. A short form of the revised conflict tactics scales, and typologies for severity and mutuality. Violence Vict 2004;19:507-20.

25 Reichenheim ME, Klein R, Moraes CL. Assessing the physical violence component of the revised conflict tactics scales when used in heterosexual couples: an item response theory analysis. Cad Saude Publica 2007;23:53-62.

26 Bates LM, Schuler SR, Islam F, et al. Socioeconomic factors and processes associated with domestic violence in rural Bangladesh. Int Fam Plan Perspect 2004;30:190-9.

27 Filmer D, Pritchett LH. Estimating wealth effects without expenditure data--or tears: an application to educational enrollments in states of India. Demography 2001;38:115-32.

28 Sharker MY, Nasser M, Abedin J, et al. The risk of misclassifying subjects within principal component based asset index. Emerg Themes Epidemiol 2014;11:6.

29 Vyas S, Kumaranayake L. Constructing socio-economic status indices: how to use principal components analysis. Health Policy Plan 2006:21:459-68.

30 Gardner W, Mulvey EP, Shaw EC. Regression analyses of counts and rates: Poisson, overdispersed Poisson, and negative binomial models. Psychol Bull 1995:118:392-404.

31 Gagnon DR, Doron-LaMarca S, Bell M, et al. Poisson regression for modeling count and frequency outcomes in trauma research. J Trauma Stress 2008:21:448-54.

32 Maldonado RC, Watkins LE, DiLillo D. The interplay of trait anger, childhood physical abuse, and alcohol consumption in predicting intimate partner aggression. $J$ Interpers Violence 2015;30:1112-27.

33 Perneger TV. What's wrong with Bonferroni adjustments. BMJ 1998:316:1236-8.

34 SAS Institute Inc [program]. Cary, NC: SAS/ACCESS, 2013.

35 Edmonds JK, Paul M, Sibley LM. Type, content, and source of social support perceived by women during pregnancy: evidence from Matlab, Bangladesh. J Health Popul Nutr 2011;29:163-73

36 Kabeer N. Between affiliation and autonomy: navigating pathways of women's empowerment and gender justice in rural Bangladesh. Dev Change 2011:42:499-528.

37 Cohen S, Doyle WJ, Skoner DP, et al. Social ties and susceptibility to the common cold. JAMA 1997:277:1940-4.

38 Berkman LF, Syme SL. Social networks, host resistance, and mortality: a nine-year follow-up study of Alameda County residents. Am J Epidemiol 1979:109:186-204. 